\title{
Emission management system in the Russian Federation: necessity for reforming and future adaptation of the western experience
}

\author{
A. Y. Nedre, R. A. Shatilov \& A. F. Gubanov \\ Federal State Unitary Enterprise "Scientific Research Institute for \\ Atmospheric Air Protection”, Russian Federation, Russia
}

\begin{abstract}
Currently, emission management is carried out in the Russian Federation on the basis of hygienic standards which is, in turn, based on the calculations of emission dispersion from source. The aim of this standardization is bringing into compliance with air quality standards for the human health maximal allowable concentration (MAC) of pollutants in the atmospheric air for human health. This article gives a brief description of this standardization method. This approach of standardization has been used in Russia since 1986, but, unfortunately, it seems in vain. There is continuous growth of pollutant emissions in Russia from stationary and mobile sources and, therefore, there is an increase in the number of cities where the air quality standards are exceeded. This article covers the historical data concerning the emission growth and related increase of the number of cities where air quality standards are exceeded. Moreover, this standardization method does not engage the introduction of the best available techniques (BATs) neither does it include evaluation and regulation of the impact on vegetation. The western approach which is based on the usage of BATs and critical loads is the most perspective from our point of view. However, this process must be coordinated with the economic capabilities of the Russian business community because the new requirements would be a significant additional financial burden. This paper contains information on the experience gained by the individual industries which began to proceed with the determination of the BATs. Finally, the concept of the modernization of the emission management system in Russia, for the years 2008-2010 is also described in brief.
\end{abstract}

Keywords: emission management, Russian Federation, BAT, MAC MPE, sanitary standard, atmospheric air quality standards. 


\section{The trends of atmospheric pollutant emissions and atmospheric pollution status in the cities of the Russian Federation}

Observations over atmospheric pollution are being carried out in 251cities of the Russian Federation. The regular observations are being carried out on the 629 stationary sites.

The results of these observations show that the level of atmospheric pollution in the cities is still significantly high. The level of atmospheric pollution in $69 \%$ of all cities is extremely high whilst a low level of atmospheric pollution is observed only in $17 \%$ of all cities [1].

On the whole, $38 \%$ of the urban population lives within the territories where the observations over the atmospheric pollution are not carried out while $55 \%$ (58,2 million of people) - within the cities with high and extremely high level of atmospheric pollution. In the year 200665 million people lived in the 206 cities where the average annual concentrations of one or several substances exceeded the MAC. During the reporting period the average annual suspended materials concentrations exceeded the MAC in 64 cities, benzo(a)pyrene concentrations in 160 cities, nitrogen dioxide - in 102 cities, formaldehyde concentrations - in 125 cities.

The priority list consists of 10 cities with the aluminium industry and ferrous metallurgy, 7 cities with the chemical and petrochemical enterprises, oil production and distribution enterprises, as well as a lot of cities with the enterprises of the fuel and energy sector.

The high level of atmospheric pollution in almost all of these cities is associated with high benzo(a)pyrene and formaldehyde concentrations, in 26 cities - with high nitrogen dioxide concentrations, in 14 cities - with high particulate matter concentrations, in 11 cities - with high phenols concentration.

In the year 2006 the maximum concentrations of the pollutant substances in the atmospheric air exceeded $10 \mathrm{MAC}$ level in 26 cities with the total population equal to 14,7 million people [1].

After the USSR collapse and denationalization of the economics the constant reduction of emissions generated by stationary sources in the Russian Federation was occurring during the years 1990-1998 [2]. The increase of emission amount was detected only after the economic default which occurred in the year 1998. The increase of road transport emissions had started a little bit earlier - since 1997; thereby, the contribution of these emissions into total emissions rises permanently because of growing motor-vehicle pool (mainly due to the individual owners (private cars)) (See Table 1).

Table 2 includes the list of the cities, where the contribution of the road transport into the total emissions exceeded $80 \%$ (in the year 2006). 
Table 1: The dynamics of total pollutant emissions in ambient air in the Russian Federation during the years 1990 - 2005.

\begin{tabular}{|l|l|l|l|l|l|l|}
\hline $\begin{array}{l}\text { Total } \\
\text { emissions }\end{array}$ & 1990 & 1995 & 1997 & 1998 & 2000 & 2005 \\
\hline $\begin{array}{l}\text { Stationary sources, mln. } \\
\text { of tons }\end{array}$ & 34,7 & 22,2 & 19,8 & 18,9 & 19,4 & 20,3 \\
\hline $\begin{array}{l}\text { Automotive transport, } \\
\text { mln. of tons }\end{array}$ & 20,9 & 14,5 & 14,4 & 15,3 & 15,7 & 17,4 \\
\hline $\begin{array}{l}\text { Total from stationary } \\
\text { sources and automotive } \\
\text { transport, mln. of tons }\end{array}$ & 55,6 & 36,7 & 34,2 & 34,2 & 35,1 & 37,7 \\
\hline $\begin{array}{l}\text { St. sources/ Automotive } \\
\text { transp. (\%) }\end{array}$ & 37,6 & 39,5 & 42,1 & 44,7 & 44,7 & 46,2 \\
\hline
\end{tabular}

Table 2: The list of the cities with dominant emission contribution from road transport into the total urban emissions ( $80 \%$ and more) subject to the amount of road transport emissions equal to, at least, 50000 tons per year.

\begin{tabular}{|l|c|c|}
\hline \multicolumn{1}{|c|}{ City } & $\begin{array}{c}\text { \% of road transport } \\
\text { contribution }\end{array}$ & $\begin{array}{c}\text { Road transport } \\
\text { emissions (thousand of } \\
\text { tons per year) }\end{array}$ \\
\hline Sochi & 96,8 & 92,65 \\
\hline Vladikavkaz & 94,5 & 89,15 \\
\hline Moscow & 92,5 & 1233,0 \\
\hline Yekaterinburg & 92,2 & 201,2 \\
\hline Krasnodar & 92,0 & 113,1 \\
\hline Rostov-on-Don & 91,1 & 119,8 \\
\hline Saint-Petersburg & 90,5 & 500,9 \\
\hline Voronezh & 89,1 & 102,4 \\
\hline Tyumen & 85,6 & 71,1 \\
\hline Kaliningrad & 83,7 & 57,7 \\
\hline
\end{tabular}

\section{The basic reasons for the necessity of the air protection activity reforming}

The basic reasons which ground the necessity for reforming of the air protection activity in the Russian Federation could be described as follows:

- the application of the existing principles of atmospheric air quality management which was developed in the 1970 s of the last century resulted in the exceedance of the atmospheric air quality standards in more than 200 cities. Notably, this number changed slightly during the years 2000-2005 in spite of the intensive development of the system of sanitary regulation and ecological monitoring; 
- the existing system concerning atmospheric air quality management is based on the bulky sanitary calculations of the dispersion. It prevents the switching on the advanced clean technologies;

- the necessity for the integration of the Russian Federation into the international economical and political systems requires the approximation of the national air protection legislation and the current legislative systems of the economically developed countries and their international associations which are based on other principles.

\section{Regulatory norms are the basis for the emission management in the Russian Federation}

The most important trend of the air protection activity in the Russian Federation is the norm setting for emissions of the pollutant substances into the atmosphere since it defines the main target of the air protection activity - emission reduction value which is necessary for the attainment of the appropriate atmospheric air quality standards.

\subsection{Types of regulation}

There are three types of regulation in the Russian air protection legislation:

- sanitary regulation for the attainment of air quality standards allowable for public health;

- ecological regulation for the attainment of air quality standards allowable for the elements of the environment;

- technical regulation for the attainment of the specific discharges per the production unit with respect to the best available technology.

The combined and/or the selective application of these three regulation methods allows solving nearly any task in the field of environment protection against the pollution.

\subsection{Sanitary regulation}

For many years, the existing Russian regulation system concerning the emissions of the pollutant (harmful) substances into the atmospheric air is based upon the accounting of the sanitary standards related to the atmospheric air quality which regulate the allowable concentration levels of the harmful substances in the atmospheric air for the residential areas.

Sanitary standards have been developed for more than 2000 harmful substances and they allow calculation of the adverse effects on the atmospheric air caused by a great number of harmful substances. In order to calculate pollutant ventilation in the atmospheric air we use the general calculation method OND-86 which is based upon the solution of equation concerning atmospheric diffusion. The calculation results concerning the pollution ventilation in the atmospheric air caused by different sources, as well as background air pollution are used for the development of the maximum permissible emissions and temporary agreed emissions for the enterprises. 
During the application of this method the following problems have been revealed:

- the inconsistency of its application in sparsely populated regions where the residential area is located far from the emission source (for example, gastransmission station in tundra), that could be used for the justifying of any standard by means of dispersion calculations for the hundred of kilometres;

- the inconsistency of its application in populated regions where the monitoring of atmospheric pollution shows the stable absence of any MPE exceedance since in that case the actual emissions automatically turn into standards;

- the absence of the accounting for road transport emissions and mutual influence of the neighbouring enterprises.

\subsection{Ecological regulation}

The trend of air protection activity could be fully reflected by ecological regulation which supposed the adoption of such emission limitations which allow the compliance of the all maximum permissible (for the objects of ecological interest) atmospheric air quality standards. There are two world widespread standards of this kind:

- the maximum permissible concentrations of the pollutant substances for the vegetation and wildlife objects (in the Russian Federation such MPC are adopted for the several species of vegetation for the region of the Lake Baikal and "Jasnaya Polyana" zone in the Tula region);

- the critical loads in terms of maximum allowable depositions per unit area. (The given standards are adopted for the European part of the Russian Federation within the framework of the Convention on Long-Range Transboundary Air Pollution - the Russian Federation is a part of this Convention.)

\section{Trends of the technical regulation development in the Russian Federation}

The most favourable tool to introduce the advanced clean technologies in the developing economy is the technical regulation. It is supposed that this regulation type will be implemented in the Russian Federation in several stages. The first stage includes the determination of the specific emissions per production unit of the enterprise which belong to one sector but use different technologies. The second stage includes the determination (by means of the update values) of the best available techniques while the appropriate specific emissions turn into the technical standards. The third stage includes the determination of the attainment dates (within the discussions with the business community). The final stage includes the adoption of these standards by means of the special legislative act.

The existing Russian law "on the atmospheric air protection" requires granting the emission permit of the pollutant substances is the subject to the 
technical emission standards. The abovementioned law also provides the definition of the technical emission standards.

Our institute made its own contribution and has developed the Programme for the implementation of the technical standards in the Russian Federation.

\subsection{Programme for the implementation of the technical standards in the Russian Federation}

As we see it, the switch on of the implementation of the technical emission standards for ambient air should be performed in two stages:

1st stage:

- development of the national methodological and information centre on the implementation of the technical regulation;

- analysis of the actual situation + the gathering of the appropriate data;

- adoption of the specific emission standards for the existing enterprises (sectoral specific emission standards).

In order to implement this stage it is necessary to develop the following national documents:

- the method for development of the specific emission standards for the existing enterprises;

- the order of consideration and agreement of the specific emission standards for the existing enterprises;

- the list of objects (inventories) which should be regulated with the help of the technical emission standards;

- the programme on the development of the federal sectoral technical emission standards;

- the order of the accounting of the specific emission standards during the adoption of the standards (limits) concerning the emissions of the pollutant substances into the atmosphere;

- the order of the accounting of the specific emission standards during the adoption of the standards (limits) concerning the emissions of the pollutant substances into the atmosphere for the projected enterprises.

2nd stage:

- development of the federal technical emission standards and its implementation within the state regulation of ambient air pollutant emissions.

In order to implement this stage it is necessary to develop the following national documents:

- the order of the development and adoption of the technical emission standards;

- the order of the development and exploitation of the data related to the best available techniques during the development and adoption of the technical emission standards subject to the ecological and economical criteria;

- the guidance on the accounting of the technical emission standards during the adoption of maximum permissible emissions and temporary agreed emissions (emission limits) of the pollutant substances into the atmospheric air. 


\subsection{The list of objects which should be regulated with the help of the technical emission standards}

Moreover, our institute prepared in 2007 "The list of objects (inventories) which should be regulated with the help of the technical emission standards". This list includes those types of economic activities (production, technological processes) which made the biggest contribution into the emissions of the pollutant substances into the atmosphere of the Russian Federation and become a reason for the high pollution level in the cities.

This list includes:

\section{Mining operations}

- Oil extraction enterprises

- Crude oil and associated gas extraction

Manufacturing activity

Metallurgical production

- Cast-iron and steel production

- Nonferrous metal production from the ores and concentrates

- Aluminium production

- Copper production

- Production of the other nonferrous metals

Electricity, steam and hot water generation

- Electricity generation by thermal power plants

- Steam and hot water generation (thermal energy) by thermal power plants

- Steam and hot water generation (thermal energy) by other power plants and industrial isolated generating plants

- Steam and hot water generation (thermal energy)

\section{Petrochemicals production}

Chemical production

- Synthetic rubber production

- Rubber article production

- Rubber tire, casing and innermost tire production

- Production of the non vulcanized caoutchouc and products made out of non vulcanized caoutchouc

\subsection{The scope of the technical emission standards}

We plan to use the technical emission standards subject to the BAT within the framework of Russian emission regulation system as follows:

- in the populated areas where the exceedance of the maximum one-time permissible concentrations (developed for the protection of public health) is registered, it is necessary to adopt the maximum allowable hygienic standards (not higher than technical emission standards) derived from the summary dissemination calculations,

- in the populated areas where the exceedance of the maximum one-time permissible concentrations (developed for the protection of public health) is not registered, it is necessary to adopt the maximum allowable emission standards on the basis of the technical emission standards, 
- for the enterprises which affect the environmental compartments, it is necessary to adopt the maximum allowable ecological emission standards (not higher than technical emission standards) on the basis of the dispersion calculations,

- during the decision-making process concerning the allocation of the new enterprise, it is necessary to access its contribution into the total pollution on the basis of the dispersion calculations provided that its emissions will not exceed the technical emission standards,

- during the development of programmes concerning the economic advancement of the territories, it is necessary to access the contribution of the new enterprises into the depositions of the pollutant substances in order to check the compliance with the critical loads provided that emissions of these enterprises will not exceed the technical emission standards.

\subsection{Russian experience concerning the adaptation of the technical regulation}

Currently, there is only one rule "on the requirements concerning the emissions of the harmful (pollutant) substances generated by the vehicles put into circulation at the territory of Russian Federation" (RF Government regulation from the 12th October of 2005, №609). It includes direct references to the nonmandatory documents (UNECE rules) - analogues of the international standards. This decision was supported by all concerned parties, and uppermost, by the motor industry which is against the double standards. The phase-in of the international standards in Russian Federation (subject to the economic development and material and technical base) is stipulated up to the year 2014 .

This situation became possible not only because of growing foreign-made car fleet but also because of the allocation of automotive production to the territory of the Russian Federation. These enterprises (technologies) entailed the introduction of the western standards concerning the emissions generated by the automotive vehicles.

The situation in other economic sectors is different. Thus, we believe it is necessary to adopt the technical emission standards for the most of the Russian producing units on the basis of the inventories concerning the existing technologies (in the country). Several major Russian companies have already begun to assess the ecological compatibility of the existing technologies and equipment in comparison with the international analogues. As a part of this work the specific emission values and sectoral standards related to the specific emissions have been adopted.

In particular, the work on the adoption of the specific emissions for the transpolar branch of the JSC "MMC Norilsk Nickel" must be completed in the nearest future; the work on the adoption of the specific emission values for the JSC "MMC Kolskaya" has been started recently - the list of regulated substances has been already adopted while the standard values for the specific producing units are being developed at the moment; the same work has been conducted since 2007 in the UC RUSAL company (the development of the sectoral method for determination of the technical emission standards for the UC RUSAL enterprises). It is planned to conduct the work (to be agreed with the 
Scientific Institute for Atmospheric Air Protection) on the adoption of the specific emission standards for the basic equipment which is applied in the heat power industry. There are also some interesting best practices concerning the paper-pulp and glass industries.

It is planned to adopt, on the basis of the obtained results, the sectoral specific emission standards and, subsequently, the federal technical emission standards.

\section{References}

[1] State report about the state and protection of the environment in the Russian Federation in 2006, Part 1 Atmospheric air, Moscow, pp. 9-10, 2007.

[2] Annual report on pollutant emissions in atmospheric air of cities and regions of the Russian Federation in 2006, St. Petersburg, pp. 83-85, 2007. 